\title{
A Comparative Analysis of Performance by Graduate and Undergraduate Students in an MEP Course
}

Dr. Ifte Choudhury, Texas A\&M University 


\title{
A Comparative Analysis of Performance by Graduate and Undergraduate Students in an MEP Course
}

\begin{abstract}
Mechanical, Electrical, and Plumbing (MEP) course is offered both at undergraduate and graduate levels in schools of construction science in the United States. The course is required for graduate students who do not have any exposure to these materials at an undergraduate level. The author offered this course to both the groups combined together in Fall 2014. The purpose this study was to find out whether there is difference in performance in the course between graduate and graduate students. There were 27 graduate and 51 undergraduate students enrolled for this class. An analysis of the data indicated that there is a statistically significant difference in performance (measured by 6 assignments, 10 in-class quizzes, and three major exams), between the two groups. A stepwise regression analysis was used to analyze the data.
\end{abstract}

Keywords: MEP, Student Performance, Graduate Students, Undergraduate Students

\section{Introduction}

An academic leveling course provides a summary or overview of the core subjects associated with a program of study. It provides a comprehensive review of all the foundational material associated with a graduate degree program. As a program prerequisite, a leveling course ensures that students are leveled to the program of study as they start it. For the graduate level construction management program at a particular university in Texas, the leveling courses have to be completed by students holding an undergraduate degree in a non-construction field. The purpose of the academic leveling course is to help develop the students' foundational knowledge of the discipline so that they can complete the program successfully.

Upon arrival new students holding an undergraduate degree in a non-construction field are required to take a placement exam in the following 5 areas:

- Construction Practices

- Construction Estimating

- Construction Scheduling

- Mechanical, Electrical, and Plumbing

- Structural Principles and Practices

A minimum score of 80 is required to pass each placement exam. Those who do not pass any of the placement exams are required to take the corresponding leveling courses.

Even though all these courses are also taught at undergraduate level, but they are offered separately to the graduate students. In the Fall of 2014, the graduate students were merged together with the undergraduates for a Mechanical, Electrical, and Plumbing (MEP) course.

Since the class comprised of two different groups of students, it was attempted to determine whether the academic performance of the graduate students was significantly different than that of the undergraduate students taking the course. 


\section{Review of the Literature}

\section{Graduate vs. Undergraduate Students}

A graduate student is one who studies for an academic degree higher than the one received after four years of study at a college or a university. Graduate programs are more concentrated courses of study and expectations regarding the quality and quantity of a student's academic work are greater than those of an undergraduate student. Graduate programs also entail:

- Focused studies in a specific discipline with fewer elective possibilities

- Rigorous evaluation of student works by professors and peers

- Smaller classes with much student interaction

- Work experience via teaching, and/or research

Studies indicate that in a combined class of graduate and undergraduate students taking the same course, graduate students score better than the other group ${ }^{1,2,3}$. Friday et al. $^{2}$ argue that this difference is probably because of differences in age, maturity, and work experiences between the two groups. A study by Trueman \& Harley ${ }^{4}$ shows that mature students have more timemanagement skill than traditional entry undergraduate students. This may also be a factor for graduate students to perform better. A recent study on performance by direct-entry versus graduate-entry medical students, Dugan et al. ${ }^{1}$ found that the graduate-entry students did significantly better in their senior dissertation assessment.

A large number of students suffer from test anxiety that results in poor performance. In one of the very early studies dealing with this phenomenon, Hembree ${ }^{5}$ analyzed the performances of 562 students ranging from elementary to college levels. He found that test anxiety reduced the performance of students at every level. However, the study indicated that undergraduates had a higher level of test anxiety than the graduate students.

There are a wide range of articles written about good practices of both undergraduate and graduate education. Chickering \& Gramson ${ }^{6}$ offered a framework for institutional improvement based on years of evidence regarding education at an undergraduate level. The authors maintained that good practice at this level entails:

- Contact between faculty and student

- Reciprocity and cooperation among students

- Active learning

- Prompt feedback

- Emphasis on timeliness for completion of tasks

- Setting high expectations

- Respect for diverse talents and ways of learning

Based on the model developed by Chickering $\&$ Gramson $^{6}$, quite a few researchers have ventured to formulate guidelines for graduate student engagement ${ }^{7,8,9}$. Pontius \& Harper ${ }^{7}$ offered a set of philosophical principles to guide graduate students:

- Striving to eradicate marginalization

- Meaningful orientation to institution beyond academic units

- Investment of resources in communication 
- Felicitation of opportunities for community building and multicultural interaction

- Holding meaningful dialogue

- Felicitation of outreach, workshops, and services

- Assessment of satisfaction, needs, and outcomes

Clearly, there seems to be a subtle difference between graduate and undergraduate education on a philosophical level. If there is a difference in student engagement, it is likely to be reflected in student performance in a same academic course.

\section{Other Factors of Student Performance}

Even though the purpose of this study was to find out the effect of practice tests on student performance, it was necessary to explore other predictors that may have significant relationship with this dependent variable. Class attendance is considered by many researchers as one such predictor. There is a wide body of literature that indicates an inverse relationship between academic achievement and class attendance. Student absenteeism is an important issue in institutes of higher learning here in the US. Class attendances, at least in practice, are optional in most schools. Although instructors have different outlook and policies toward attendance, most of them would like them to attend the classes to maintain a vibrant teaching-learning atmosphere. Most of them also associate class attendance with academic achievement. It is generally accepted that attending classes is an important aspect of college experience. ${ }^{10}$

Studies reveal that there is a relationship between absenteeism and student performance in courses ${ }^{9}$. The hypothesis that there is a strong relationship between class attendance and student learning has been investigated empirically in journals of higher education. It is not surprising that most studies have found an inverse relationship between being absent from the class and course performance $\mathrm{e}^{10,11,12,13}$.

Studies have been conducted on the inverse relationship between absenteeism and student performance in different courses at college level. As long back as in the 1970 's, Jenne ${ }^{14}$ found that attendance played a major role in a health science course. Jones ${ }^{15}$ reported that there is a negative correlation between absences from class and grades in a psychology course, irrespective of ethnicity or gender of the students. Romer ${ }^{16}$ reports a similar finding on a study related to intermediate microeconomic theory.

Devadoss and Foltz ${ }^{13}$ conducted a study on the effect of a number of predictor variables on performance in agricultural economics. They conclude that the study "provides strong empirical evidence of the positive influence of class attendance on student performance" (p. 506). Findings of another study on course in principles of economics show evidence of an inverse relationship between absenteeism and performance is statistically significant when students miss a sizeable number of classes. ${ }^{17}$

Investigations on relationship between absenteeism and student performance in construction science courses are negligible. However, there is on recent study by Senior ${ }^{18}$ that explores such relationship for course in construction management. The results of the study indicate a statistically significant correlation between missed classes and final student grade in the course. 
Many courses in construction management comprise of concepts or ideas that students need to comprehend in order to succeed in follow-on courses. An in-depth understanding of the fundamentals of a course helps them transfer knowledge to from one course to another. Bransford et al. ${ }^{19}$ argue that it necessary for students to evaluate their learning current level of understanding continuously. In order to do that, they require constant feedback from instructors. Different methods are used by faculty at college level to enhance and improve such understanding by providing instant feedback ${ }^{20}$. Most widely adopted methods are giving short tests and assigning problem-solving home works.

There are, of course, few studies that report no relationship between attendance and performance. Browne, et al. ${ }^{21}$ did not find any positive effect on attending lectures and student grades on tests in an economics course. Similarly, findings by Buckles \& McMahon $^{22}$ do not suggest any significant effect of class attendance on student performance.

Assignments or home works may also have a significant role to play in enhancing a student's indepth understanding of course materials ${ }^{23}$. Apart from being considered as tools for enhancing student learning, home works and quizzes have been found to have a positive relationship with overall student performance ${ }^{24}$.

The effect of one other variable on performance that has been tested by many researchers is gender. Some studies indicate that men have more positive attitude toward education in engineering and science than women ${ }^{15,25}$. It is reflected by their performance in relevant courses. However, there are other studies that do not report any correlation between gender and student performance ${ }^{25,26 \text {, }}$ 27 .

In view of the findings from this review of the literature, it was decided to include a few other variables in the model for analysis of the relationship between academic level of students and student performance. These variables include: absenteeism, assignments, gender, and in-class quizzes.

\section{Methodology}

\section{Study Population}

The study population consists of students who registered for a Mechanical, Electrical, and Plumbing course at an undergraduate and graduate level in a state university for Fall semester in 2014. There were 27 graduate ( 9 females and 18 males) and 51 undergraduate students ( 4 females and 47 males) enrolled for this class. The sample size includes the total population of 58 students.

\section{Data Collection}

Data related to the study was collected from the instructor's own database. The unit of analysis was the student. 


\section{Variables and their Operationalization}

Exam Grade (EXAM). It is the sum of all the scores made by a student in two tests given till the study was conducted. It was measured by the numerical grades obtained by the student in the tests.

Absenteeism (ABSENT). It is the record indicating the complete absence of the student from class meetings. It was measured in number of class meetings missed by the student.

Assignments (ASSN). It is the performance by the student for a particular assignment related to a topic covered by the course and done at home. It was measured by the cumulative numerical grade obtained by the student in all assignments till the study was conducted.

Gender (GENDER). It indicates the gender of the student. It was a dummy variable, operationalized by assigning a value of 1 in case of a male student and 0 for a female student.

Level (LEVEL). It indicates academic level of the student. It was a dummy variable, operationalized by assigning a value of 1 in case of a graduate student and 0 otherwise.

Quiz (QUIZ). It is the performance by a student in a short, previously unannounced, test held in the class related a particular course topic. It was measured by the cumulative numerical grade obtained by the student in all quizzes till the study was conducted.

\section{Analysis}

A stepwise regression analysis was performed to explore the data. This is an automatic procedure for statistical model selection in cases where there are a large number of potential explanatory variables. Forward selection procedure was used. The procedure involves selection of variables that are statistically significant. Following model was used for the purpose:

EXAM $=\beta_{0}+\beta_{1} \mathrm{ABSENT}+\beta_{2} \mathrm{ASSN}+\beta_{3}$ GENDER $+\beta_{4} \mathrm{LEVEL}+\beta_{5} \mathrm{QUIZ}+\varepsilon \quad$ Eqn. (1)

where $\beta_{0}=$ intercept, $\beta_{1}=$ the coefficient of ABSENT, $\beta_{2}=$ the coefficient of ASSN, $\beta_{3}=$ the coefficient of GENDER, $\beta_{4}=$ the coefficient of LEVEL, $\beta_{4}=$ the coefficient of QUIZ, and $\varepsilon=$ error term.

\section{Results}

The results of the analysis are shown in Table 1. 
Table 1: Statistical Analysis for EXAM

\begin{tabular}{|l|r|r|r|r|}
\hline Variable & Intercept & $\begin{array}{l}\text { Regression } \\
\text { Coefficient }\end{array}$ & $\mathrm{T}$ & $\mathrm{p}<|\mathrm{T}|$ \\
\hline Intercept & 33.86 & & 8.52 & $<0.001$ \\
\hline LEVEL & & 9.16 & 7.22 & $<0.001$ \\
\hline QUIZ & & 1.07 & 2.09 & 0.040 \\
\hline $\begin{array}{l}\text { F-value of the Model: } \\
39.53\end{array}$ & $\begin{array}{l}\mathrm{p}>\text { Model F } \\
=<0.001\end{array}$ & Model $\mathrm{R}^{2}=0.52$ & \multicolumn{2}{|c|}{ Adjusted model $\mathrm{R}^{2}=0.51$} \\
\hline
\end{tabular}

The results indicate that only LEVEL and QUIZ were retained in the model. The excluded variables were ABSENT, ASSN, and GENDER.

The F statistic of a model basically tests how well the model, as a whole, accounts for the dependent variable's behavior. The F-value of this particular model was found to be statistically significant at less than the 0.001 level.

An important aspect of a statistical procedure that derives model from empirical data is to indicate how well the model predicts results. A widely used measure of the predictive efficacy of a model is its coefficient of determination or $\mathrm{R}^{2}$-value. If there is a perfect relationship between dependent and predictor variables, $\mathrm{R}^{2}$ is 1 . In case of no relationship between dependent and predictor variables, $\mathrm{R}^{2}$ is 0 . Predictive efficacy of this particular model was found to be moderately high with an adjusted value of 0.51 . Such values are considered to be satisfactory related to empirical studies in social sciences ${ }^{28}$. The independent variables included in the model explained about 51 percent of the variance.

The results indicated that overall test grade of a student, measured by EXAM, in a Mechanical, Electrical, Plumbing course offered at a state university is positively correlated with the academic level of students (Figure 1) at the level of significance of less than 0.001. This relationship exists in the presence of quiz performance, which is known to have some effect on overall student performance. The level of significance of the relationship between overall test grade and quiz performance is less than 0.05. The results implied that when academic level is taken into consideration, the mean exam grade of a graduate student increases by more than 9 points. The mean exam grade, however, would increase by 1.07 points for every point earned in a quiz, for all students. 


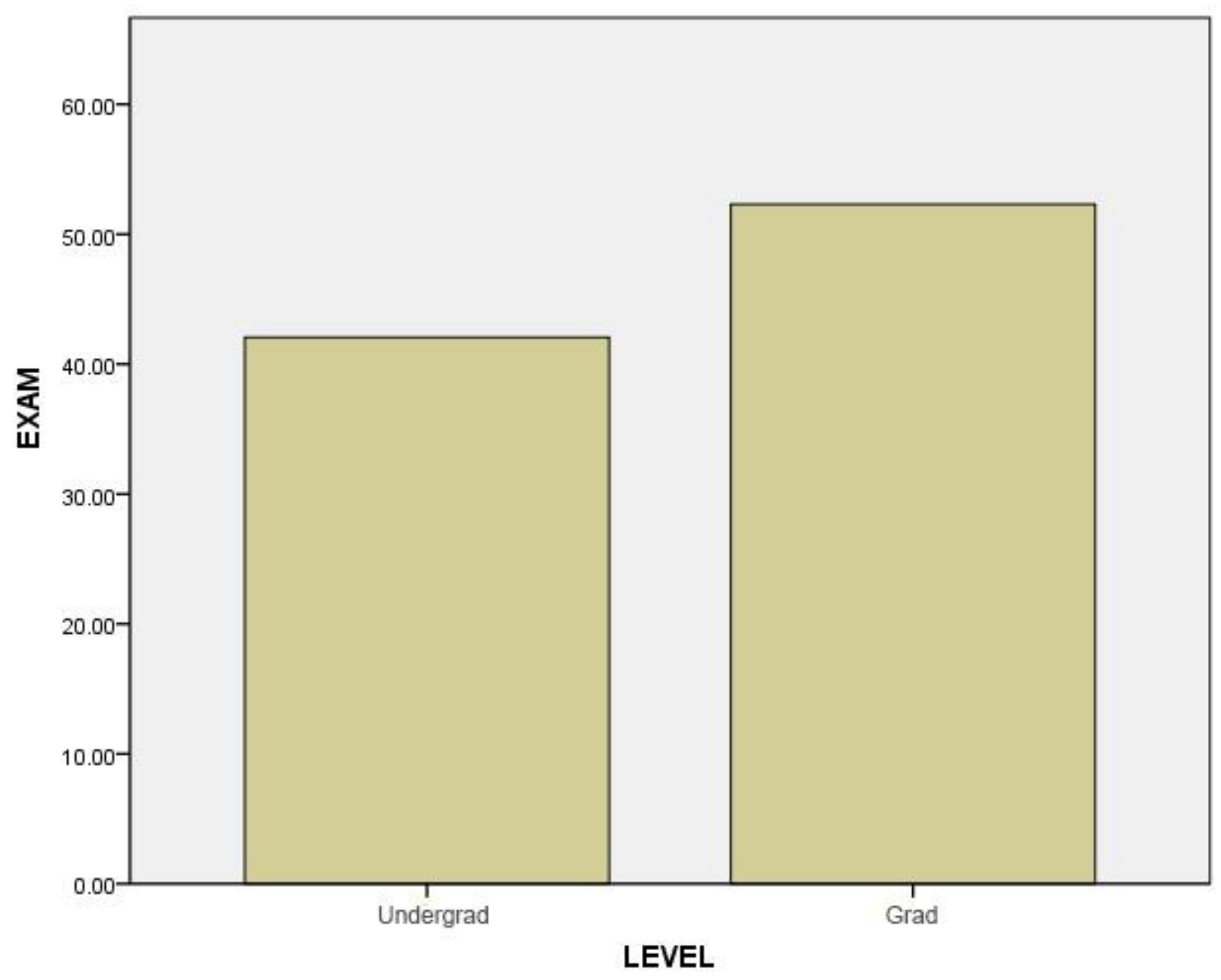

Figure 1. Relationship between EXAM and LEVEL

\section{Discussions}

The results of the statistical analysis are meaningful in the sense that it provides support to the hypothesis graduate students perform better than the undergraduate students taking the same course. The study shows that academic performance of the graduate students is significantly better than that of the undergraduate students in a Mechanical, Electrical, and Plumbing course offered at a state university.

A poor performance quizzes indicate an inadequate understanding of the materials discussed in the class. They eventually affected a student's overall performance in the course.

A surprising aspect of the study was the exclusion of absenteeism as a predictor of student performance. The author has conducted a number studies that indicated that students having a higher number of absences from class tend to perform poorly in such a course. One possible explanation could be that a student, without attending the classes, could have good grasp of the course contents only by studying the online materials uploaded by the instructor. 
Exclusion of assignments as a correlate of student performance is understandable. They were essentially home works required to be completed by the students in a certain period of time, sometimes over a week. They could seek help from their peers to complete these tasks without having a complete understanding of the materials.

\section{Conclusions}

The study provides a moderate support to the hypothesis that there is a statistically significant difference in academic performance between graduate and undergraduate students taking the same course simultaneously. Graduate students perform better than the undergraduates. It gives rise to the question whether a course like this should be offered in the same class to two academically diverse groups of students. Obviously, the graduate students grasped the concepts and materials faster than their counterparts, and could use them well during the exams. If it were a separate class dedicated to the graduate students, the instructor could probably dig deeper into the constructs of the course.

However, the results of the study must be taken with some caution. It was done for only one course in a semester and, therefore, the findings cannot be generalized. The study will hopefully generate enough interest to do further research on predicting performance of academically diverse groups of students in other courses.

Bibliography

1. Dugan, E.M. et al. (2014). "Enhanced research assessment performance in graduate vs. undergraduate-entry medical students: implications for recruitment into academic medicine," QJM: An International Journal of Medicine, 107(9), 735-741.

2. Friday, E. et al. (2006). "A multi-semester comparison of student performance between multiple traditional and online sections of two management courses," Journal of Education for Social Work, 19(2), 77-84.

3. Nelson, K. (1983). "Difference in graduate and undergraduate performance in a core research course," Institute of Behavioral and Applied Management, 66-81.

4. Truman, M. \& Hartley, J. (1996). "A comparison between time-management skills and academic performance of mature and traditional-entry university students," Higher Education, 32, 199-215.

5. Hembree, R. (1988). "Correlates, causes, effects, and treatment of test anxiety," Review of Educational Research, 58, 47-77.

6. Chickering, A.W. \& Gramson, Z. (1987). "Seven principles of good practice in undergraduate education," AAHE Bulletin, 39(7), 3-7.

7. Pontius, J.L. \& Harper, S.R. (2006). "Principle of good practice in graduate and professional student engagement," New Directions in Student Services: Wiley Interscience, 115, 48-58.

8. Poock, M.C. (2002), "Graduate student orientation: Assessing needs and methods of delivery," Journal of College Student Development, 43(2), 231-245.

9. Nerad, M. \& Miller, D.S. (1996), "Increasing student retention in graduate and professional programs," In J.G.Haworth (ed.), Assessing Graduate and Professional Education: Current Realities, Future Prospects, New Directions for Institutional Research, no. 96, San Francisco: Jossey-Bass.

10. Cohn, E. \& Johnson, E. (2006), "Class attendance and performance in principles of economics," Education Economics, 14(2), 211-233.

11. Brocato, J., (1989), "How much does coming to class matter? Some evidence of class attendance and grade performance," Educational Research Quarterly, 13(3), 2-6.

12. Murburger, D., (2001), "Absenteeism and undergraduate exam performance," The Journal of Economic Education, 32(2), 99-109.

13. Devadoss, S. \& Foltz, J., (1996), "Evaluation of factors affecting student class attendance and performance," America Journal of Agricultural Economics, 78(3), 499-507. 
14. Jenne, F. H., (1973), "Attendance and student proficiency change in a health science class," Journal of School Health, 43, 125-126.

15. Jones, C. H., "Interaction of absences and grades in a college course," The Journal of Psychology, 116, 133-136, (1984).

16. Romer, D., (1993), “Do students go to class? Should they?” Journal of Economic Perspectives, 7(3), 167-174.

17. Durden, G. C. \& Ellis, L. V., (1995), “The effects of attendance on student learning," American Economic Review (Papers and Proceedings), 85(2), 101-112.

18. Senior, B. A., (2008), "Correlation between absences and final grades in a college course," Proceedings of the $44^{\text {th }}$ Annual Conference of the Associated Schools of Construction, Auburn, Alabama, April 2-6, 2008, on CDROM.

19. Bransford, J. D., Brown, A. L., \& Cocking, R. R., (eds.), (1999), “How people learn: Brain, mind, experience, and school", National Academy Press, Washington, D. C., Chap. 3, 39-66.Buckles, S. G. \& McMahon, M. E., (1971), "Further evidence on the value of lecture in elementary economics," Journal of Economic Education, Vol. 2, 138-141.

20. Freeman, M. \& McKenzie, J., (2001), “Aligning peer assessment with peer learning for large classes: the case for an online self and peer assessment system," in Peer Learning in Higher Education, Boud, D., Cohen, R., \& Sampson, J. (eds.), Kogan Page Ltd., London, Chap. 11, 156-169.

21. Browne, M. N. et al., (1991), "The impact of teachers in economic classrooms," The Journal of Economics, 17, 25-30.

22. Buckles, S. G. \& McMahon, M. E., (1971), "Further evidence on the value of lecture in elementary economics," Journal of Economic Education, Vol. 2, 138-141.

23. Douglas, S. \& Sulock, (1995), "Estimating educational production functions with correction for drops," Journal of Economic Education, 26(2), 101-112.

24. David, A. W., Flood, W. A., \& Stromsnes, W., (2001), "The use of random extra credit quizzes to increase student attendance," Journal of Instructional Psychology, 28(2), 117-120.

25. Lawson, T. J. et al., (2006), "Guiding questions enhance student learning from educational videos," Teaching of Psychology, 33(2), 31-33.

26. Kreiner, D. S., (1997), "Guided notes and interactive methods for teaching with video tapes," Teaching of Psychology, 24, 183-185.

27. Bond, N. W., (1998), “A multi-media program in associative learning,” Teaching of Psychology, 25(4), 300-302. 